\section{Enantiomeric distribution of key volatile components in Citrus essential oils}

\author{
Ivana Bonaccorsi, ${ }^{* 1}$ Danilo Sciarrone, ${ }^{1}$ Antonella Cotroneo, ${ }^{1}$ \\ Luigi Mondello, ${ }^{1,2}$ Paola Dugo, ${ }^{1,2}$ Giovanni Dugo ${ }^{1}$
}

${ }^{1}$ Dipartimento Farmaco-chimico, Università di Messina, Italy, ${ }^{2}$ Università Campus Bio-Medico, Rome, Italy.
Revista Brasileira de Farmacognosia Brazilian Journal of Pharmacognosy 21(5): 841-849, Sep./Oct. 2011

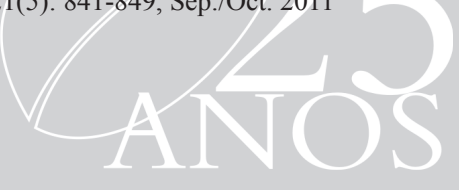

\section{Article} it is possible to reveal adulteration of different nature, such as addition of synthetic compounds, or natural components of different botanical origin, with drastic changes in the biological and olfactory properties. This study is focused on the evaluation of the enantiomeric excesses of numerous samples of different Citrus species: C. deliciosa Ten., C. limon (L.) Burm., C. bergamia, C. aurantifolia (Christm.) Swing., C. latifolia Tan., C. sinensis (L.) Osbeck, and C. aurantium L. The enantiomeric distribution is determined by direct esGC and, depending on the complexity of the essential oil, by MDGC with a chiral column in the second dimension. The research is focused on the determination of fourteen chiral components which present specific distribution in the essential oils investigated. Particular attention is given to the trend of the enantiomeric distribution during the productive season, so to identify useful parameters for quality assessment also in consideration of the wide range of variability often reported in literature. The components investigated were the following: $\alpha$-thujene, $\alpha$-pinene, camphene, $\beta$-pinene, sabinene, $\alpha$-phellandrene, $\beta$-phellandrene, limonene, linalool, camphor, citronellal, linalyl acetate, terpinen-4-ol, $\alpha$-terpineol. The use of MDGC allowed the separation of the enantiomers of camphor and citronellal, otherwise not separated by conventional esGC; however for the separation of the enantiomers of $\alpha$-pinene it was preferable to use conventional esGC. The MDGC system allowed to determine the enantiomeric distribution of camphene, $\alpha$ - and $\beta$-phellandrene in lime essential oil for the first time. The results are discussed in function of seasonal variation and, when possible, in function of the extraction technology, with particular regards to lime oils.
Received 21 Dec 2010

Accepted 10 Mar 2011

Available online 8 Jul 2011

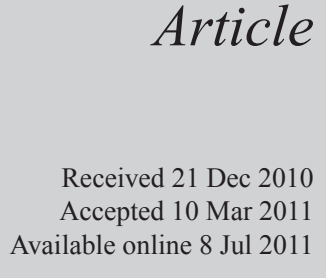

Keywords: Citrus essential oils enantiomeric purity; esGC MDGC monoterpenes 695X2011005000123

\section{Introduction}

Citrus essential oils are widely used in flavor, fragrances, food, soft drink and liqueurs, they are included in cosmetics, perfumes, detergents, bodycare products, and in a large number of pharmaceutical preparations (gynecological, ophthalmic, surgical, dentistry etc.). These essential oils are appreciated mostly for their fragrances but also for their solvent properties and their well-known antiseptic properties. Citrus as many other plants present highly characteristic distribution of some enantiomers, thus it is often possible to use this parameter for identification, characterization, genuineness and pharmacological activity assessments. In particular, by the enantiomeric distribution of key components it is possible to reveal adulteration of different nature, such as addition of synthetic compounds, or natural components of different botanical origin, which may drastically change the biological and olfactory properties. In literature numerous articles on the biological activities exerted by citrus essential oils are available. Most of these were recently revised by Bisignano \& Saija, 2011. Since essential oils are chemically complex matrices (containing tens of different compounds) their biological activity is difficult to explain. Very little is known on the effectiveness of single compounds. Many reports on the activities of essential oils often apply the terms "synergism", "antagonism", "additivity" to overcome the need of identifying the single components activities; others simply cite the main components present in the whole oil without further discussion. Few are the references available on the different biological properties exerted by pure compounds (mainly limonene and linalool) naturally present in citrus oils (Ruberto \& Baratta, 2000; Heuberger et al., 2001; Peana et al., 2002, 2006; Frum \& Viljoen, 2006; Kamatou \& Viljoen, 2008; Ozek et al., 2010). 
It is widely known that enantiomers of the same molecule possess different properties, they can work as growth regulators, support plant reproduction, defend the plants from external attacks. Within a vegetable individual enantiomers generally show quantitative differences, although sometimes they can be present as racemic mixtures, and exert different activity based on their stereochemical configuration. This study may provide useful information to stimulate researches focused on the evaluation of biological activity exerted by citrus oils by testing the properties of single enantiomers in function of their chiral purity in different citrus species.

The composition of citrus oils was deeply investigated in the last decades by modern analytical techniques. Most of the literature on the volatile fraction was recently revised by Dugo et al., 2011; the nonvolatile fraction was revised by Dugo \& Russo, 2011; the chiral compounds were revised by Mondello et al., 2011 and the carotenoid fraction by Dugo \& Giuffrida, 2011.

Recently few articles were published by our research group on the characterization of citrus oils by means of enantioselective separation (Dugo et al., 2010; Dugo et al., 2011a,b; Bonaccorsi et al., 2009.

Successful enantioselective-GC (esGC) is performed by cyclodextrin derivatives (CDD) to evaluate essential oils through the enantiomeric distribution of their optically active components. New CDD greatly enlarged the number of separable racemates and it is possible to evaluate the essential oils through several of its optically active components in a single GC run. The recovery of pure reference is not always possible and often the identification of the correct enantiomer is based on literature information.

In natural matrices the separation of enantiomers of components present at different concentrations is quite complex. Direct enantioselective GC (esGC) separation is often compromised by the presence of very large peaks (e.g. limonene in sweet orange) which overload the capillary column, and by numerous peak overlaps that occur between the enantiomers and other components, therefore different analytical approaches should be evaluated. In particular, to avoid this inconvenient and to reduce peak overlapping a good choice is the approach by multidimensional gas chromatography (MDGC). Using MDGC each peak eluting from the first dimension of the system (usually a conventional apolar column), well separated from other components, is transferred, partially or totally, to the second dimension (chiral column). It is possible to transfer numerous peaks from the first to the second dimension during the same analysis. In this study the enantiomeric distribution is determined by direct esGC or, depending on the complexity of the essential oil, by MDGC.
The determination of the chiral components with a specific distribution in each of the essential oils are investigated. Particular attention was paid to the trend of the enantiomeric distribution during the productive season, useful to determine parameters for quality assessment considering of the wide range of variability often reported in literature for specific components.

The components investigated were: $\alpha$-thujene, $\alpha$-pinene, camphene, $\beta$-pinene, sabinene, $\alpha$-phellandrene, $\beta$-phellandrene, limonene, linalool, camphor, citronellal, linalyl acetate, terpinen-4-ol, $\alpha$-terpineol.

The use of MDGC allows the separation of the enantiomers of camphor and citronellal, otherwise not separated by conventional esGC; however for the separation of the enantiomers of $\alpha$-pinene it is preferable to use conventional esGC. The MDGC system allowed to determine the enantiomeric distribution of camphene, $\alpha$ - and $\beta$-phellandrene in lime essential for the first time.

\section{Materials and Methods}

Samples

The analyses were carried out on of 251 samples of different Citrus species: C. deliciosa Ten., C. limon (L.) Burm., C. bergamia, C. aurantifolia (Christm.) Swing., C. latifolia Tan., C. sinensis (L.) Osbeck, and $C$. aurantium $\mathrm{L}$. were analyzed by esGC or by MDGC to determine the enantiomeric purity of selected compounds. All the samples were surely genuine with the exception of one commercial sample of Italian bitter orange oil. All the samples were obtained by cold-extraction by the most appropriate machines as described below. With the exception of Key lime oil Type A none of the extraction techniques used allow the contact of the oil with the acid juice of the fruits.

The 124 samples of Italian mandarin, were cold-extracted by screw press and by Brown International Corp. (BOE) machines from fruits collected during an entire productive season; The 92 samples of Italian lemon oil were cold-pressed by FMC (FMC Corporation, Citrus Machinery Divison) and BOE machines from fruits produced during an entire productive season; the eight samples of Italian bergamot oil were cold-pressed by Pelatrice machines from fruits collected during an entire productive season; the three samples of Key lime type A were produced by cold-extraction, using screw press on the crushed fruits and centrifuge to separate the oil from the emulsion; the three of Type $B$ were produced by cold-extraction (Raspatrice and Speciale) in Mexico; the two samples of Mexican 
Persian lime were cold pressed by FMC; the three genuine samples of bitter orange oil, one Italian and two from Egypt were obtained by Pelatrice machines; The seventeen samples of Italian sweet orange oil, were produced in Sicily by FMC extractors collected during an entire productive season.

\section{Analysis}

EsGC: Shimadzu GC2010 gas chromatograph equipped with a Flame Ionization Detector (FID), a split/splitless injector and an AOC-20i series autoinjector. Capillary chiral column was a Megadex DETTBS- $\beta$-(diethyl-tert-butyl-silyl $\beta$-cyclodextrin) 25 m x 0.25 mm I.D. x $0.25 \mu \mathrm{m} d_{f}$ (Mega, Legnano, Italy). Temperature program: $50-200{ }^{\circ} \mathrm{C}$ at $2{ }^{\circ} \mathrm{C} / \mathrm{min}$. Inlet pressure $96.6 \mathrm{kPa}\left(220^{\circ} \mathrm{C}\right.$ ), split mode 1:20 (gas carrier $\mathrm{He})$; injected volume, $1.0 \mu \mathrm{L}$ (1:10 in $n$-hexane); linear velocity, $35 \mathrm{~cm} / \mathrm{s}$ (constant). Data handling was made by means of GCsolution software

Multidimensional enantio-GC (MDGC) analyses were carried out on a MDGC system consisted of two GC2010 (defined as GC1 and GC2) gas chromatographs, equipped with a Deans type switch transfer device, an MS-QP2010 quadrupole mass spectrometer, and an AOC-20i autosampler (Shimadzu, Japan).

GC1 was equipped with a split/splitless injector and a flame ionization detector (FID1). The MDGC switching element, located inside the oven, was connected to an advanced pressure control (APC) system which supplied carrier gas (He) at constant pressure. GC1: column, SLB-5MS (silphenylene polymer, virtually equivalent in polarity to $5 \%$ diphenyl, $95 \%$ methylpolysiloxane) $30 \mathrm{~m} \mathrm{x} 0.25 \mathrm{~mm}$ i.d. x $0.25 \mu \mathrm{m}$ $d_{f}$ (Supelco, Milan, Italy). The operational conditions were as follows: constant inlet pressure $220 \mathrm{kPa}(300$ ${ }^{\circ} \mathrm{C}$ ), split mode 1:20 (gas carrier He), injected volume $1.5 \mu \mathrm{L}(1: 10$ in $n$-hexane), initial linear velocity 30 $\mathrm{cm} / \mathrm{s}$. Temperature program: 50 to $280{ }^{\circ} \mathrm{C}$ at $3{ }^{\circ} \mathrm{C} / \mathrm{min}$. The FID $\left(300{ }^{\circ} \mathrm{C}\right)$ was connected, via a stainless steel retention gap, to the transfer system; sampling rate: 80 s. APC constant pressure: $130 \mathrm{kPa}$.

GC2 was equipped with a split/splitless injector and a flame ionization detector (both not used in the present research). Transfer line between the two GC systems was kept at $180{ }^{\circ} \mathrm{C}$. GC2: column: Megadex DETTBS- $\beta$-(diethyl-tert-butyl-silyl $\beta$-cyclodextrin) 25 $\mathrm{m} \times 0.25 \mathrm{~mm}$ i.d. x $0.25 \mu \mathrm{m}$ df (Mega, Legnano, Italy). Temperature program: $40^{\circ} \mathrm{C}(20 \mathrm{~min})$ to $100^{\circ} \mathrm{C}$ at $1{ }^{\circ} \mathrm{C} /$ $\min$, to $160^{\circ} \mathrm{C}$ at $3{ }^{\circ} \mathrm{C} / \mathrm{min}$. Detector MS, Ion source: $200{ }^{\circ} \mathrm{C}$, Interface temp.: $220^{\circ} \mathrm{C}$, Interval scan: $40-400$ $\mathrm{m} / \mathrm{z}$, Scan speed: 2000 a.m.u. per second (5 Hz).

Identification and quantitative analysis
Peak identification was based on the results obtained from previous studies carried out in the authors' laboratory by injecting standard references and by GC-MS identification. The methods (esGC and MDGC) were tested for repeatability by triplicates with RSD values ranging from 3 to $9 \%$ (highest value refer to $(+)$ - $\alpha$-thujene) (Sciarrone et al., 2010).

\section{Results and Discussion}

The use of esGC and MDGC allowed the determination of the enantiomeric distribution of monoterpene hydrocarbons ( $\alpha$-thujene, $\alpha$-pinene, camphene, $\beta$-pinene, sabinene, $\alpha$-phellandrene, $\beta$-phellandrene, limonene) monoterpene alcohols (linalool, terpinen-4-ol, $\alpha$-terpineol), linalyl acetate, camphor and citronellal in 251 samples of essential oils of seven different citrus species. The choice of using both techniques was dictated by the complementarity of the results. In fact by direct enantioselective chromatography it is not possible to separate citronellal and camphor isomers in all the essential oils analyzed depending on the complexity of the oil. The determination of the exact value of $\beta$-phellandrene can be compromized by the coelution of the $(+)$-isomer with $\alpha$-terpinene. In this case MDGC is mandatory in order to obtain reliable results. On the other hand due to the chromatographic conditions applied in MDGC the separation of the enantiomers of $\alpha$-pinene is compromized. These enantiomers can be well separated by direct esGC. With the exception of $\beta$-phellandrene, camphor and citronellal, which were all determined by MDGC, and for the $\alpha$-pinene enantiomers, separated by esGC, the enantiomeric distribution determined by the two chromatographic techniques were in excellent agreement.

Table 1 reports the ranges determined in lemon, bergamot, mandarin, limes and sweet orange oils of the enantiomeric distribution and the total percentages in the whole volatile fraction of the fourteen components investigated. Table 2 reports the enantiomeric distribution and the total percentages in the whole volatile fraction, determined in the samples of bitter orange oil. For the quantitative composition of the oils please refer to the previously published results reported in the review by Dugo et al., 1999. Among the seven Citrus species analyzed it is possible to identify key components with characteristic enantiomeric distribution, useful for their characterization. In the graphs reported in Figure 1-4 it is possible to see the most significant seasonal behavior of the enantiomeric excesses for lemon, bergamot, mandarin and sweet orange oils. Figure 5 compares the enentiomeric excess in Key lime types A and B and Persian lime. With regards to bitter orange oil it was not possible 
Table 1. Enantiomeric distribution (ranges) determined by esGC and MDGC, and relative peak area \% determined by GC on the whole volatile fraction. Number of samples are indicated in brackets.

\begin{tabular}{|c|c|c|c|c|c|c|c|c|}
\hline & & Lemon & Bergamot & Mandarin & Key Lime & & Persian Lime & Sweet Orange \\
\hline & & Italy & Italy & Italy & Mexico & & Mexico & Italy \\
\hline & & (92) & $(8)$ & (124) & (3) & (3) & (2) & (17) \\
\hline & & & & & Type A & Type B & & \\
\hline 1 & $(+)-\alpha$-thujene & $0.7-1.5$ & $0.9-1.4$ & $0.5-0.8$ & $0.9-1.1$ & $0-1.2$ & $0.5-0.7$ & $10.2-62.0$ \\
\hline \multirow[t]{2}{*}{2} & $(-)-$ & $99.3-98.5$ & $99.1-98.6$ & $99.5-99.2$ & $99.1-98.9$ & $100-98.8$ & $99.5-99.3$ & $89.8-38.0$ \\
\hline & $\%$ & $0.27-0.54$ & $0.15-0.49$ & $t r-1.06$ & $0.27-0.43$ & & $0.46-0.6$ & $t r-0.03$ \\
\hline 3 & $(+)$ - $\alpha$-pinene & $25.5-31.5$ & $30.2-32.6$ & & $21.8-22.5$ & $22.3-23.3$ & $28.6-30.0$ & $91.1-99.4$ \\
\hline \multirow[t]{2}{*}{4} & $(-)-$ & $74.5-68.5$ & $69.8-67.4$ & & $78.2-77.5$ & $77.7-76.7$ & $71.4-70.0$ & $8.9-0.6$ \\
\hline & $\%$ & $0.88-4.40$ & $0.46-1.84$ & $1.55-5.24$ & $1.91-2.70$ & & $1.78-2.25$ & $0.36-1.40$ \\
\hline 5 & (-)-camphene & $86.2-92.4$ & $87.9-89.3$ & $44.7-48.4$ & $92.8-92.9$ & $91.8-94.6$ & $88.4-89.3$ & \\
\hline \multirow[t]{2}{*}{6} & $(+)-$ & $13.8-7.6$ & $12.1-10.7$ & $55.3-51.6$ & $7.2-7.1$ & $8.2-5.4$ & $11.6-10.7$ & \\
\hline & $\%$ & $0-0.13$ & $0-0.05$ & $\operatorname{tr}-0.02$ & $0.07-0.12$ & & $0.04-0.11$ & \\
\hline 7 & $(+)$ - $\beta$-pinene & $4.3-6.8$ & $8.5-9.6$ & $87.7-98.7$ & $3.5-4.5$ & $3.7-4.5$ & $9.4-10.3$ & $10.6-70.2$ \\
\hline \multirow[t]{2}{*}{8} & $(-)-$ & $95.7-93.2$ & $91.5-90.4$ & $12.2-1.3$ & $96.5-95.5$ & $96.3-95.5$ & $90.6-89.7$ & $99.4-29.8$ \\
\hline & $\%$ & $8.57-17.79$ & $2.97-10.70$ & $1.0-2.44$ & $18.25-25.45$ & & $10.01-12.20$ & $\operatorname{tr}-0.11$ \\
\hline 9 & $(+)$-sabinene & $12.4-15.0$ & $16.1-17.2$ & $71.3-81.5$ & $15.2-15.4$ & $15.2-15.4$ & $18.6-19.3$ & $89.8-97.5$ \\
\hline \multirow[t]{2}{*}{10} & $(-)-$ & $87.6-85.0$ & $83.9-82.8$ & $28.7-18.5$ & $84.8-84.6$ & $84.8-84.6$ & $81.4-80.7$ & $10.2-2.5$ \\
\hline & $\%$ & $1.13-2.79$ & $0.51-1.69$ & $0.10-0.59$ & $2.31-3.28$ & & $0.91-2.07$ & $0.24-0.80$ \\
\hline 11 & (-)- $\alpha$-phellandrene & $46.9-52.6$ & $49.5-54.0$ & $44.3-55.0$ & $50.9-53.7$ & $52.1-58.4$ & $55.2-55.8$ & \\
\hline \multirow[t]{2}{*}{12} & $(+)-$ & $53.1-47.4$ & $50.5-46.0$ & $55.7-45.0$ & $49.1-46.3$ & $47.9-41.6$ & $44.8-44.2$ & \\
\hline & $\%$ & $\operatorname{tr}-0.13$ & $0.01-0.18$ & $0.03-0.11$ & $0.02-0.05$ & & $\operatorname{tr}-0.05$ & \\
\hline 13 & $(-)-\beta$-phellandrene & $31.1-53.9$ & $27.6-33.7$ & $0.4-2.7$ & $63.9-65.6$ & $68.5-73.7$ & $54.5-55.1$ & $0.4-1.4$ \\
\hline \multirow[t]{2}{*}{14} & $(+)$ & $68.9-46.1$ & $72.4-66.3$ & $99.6-97.3$ & $36.1-34.4$ & $31.5-26.3$ & $45.5-44.9$ & $99.6-98.6$ \\
\hline & $\%$ & $\operatorname{tr}-0.48$ & $0.02-0.21$ & tr & tr & & tr & $0.40-1.40$ \\
\hline 15 & (-)-limonene & $1.4-1.6$ & $1.7-1.9$ & $1.6-2.2$ & $2.8-2.9$ & $2.8-3.0$ & 2.7 & 0.5 \\
\hline \multirow[t]{2}{*}{16} & $(+)-$ & 98.6-98.4 & $98.3-98.1$ & 98.4-97.8 & $97.2-97.1$ & $97.2-97.0$ & 97.3 & 99.5 \\
\hline & $\%$ & $59.57-71.82$ & $23.5-54.85$ & $65.30-77.82$ & $47.85-51.14$ & & $51.47-59.81$ & $91.15-96.10$ \\
\hline 17 & $(+)$-camphor & & $25.3-42.1$ & $17.0-36.5$ & & & & \\
\hline \multirow[t]{2}{*}{18} & $(-)-$ & & $74.7-57.9$ & $83.0-63.5$ & & & & \\
\hline & $\%$ & & $0-0.01$ & $\operatorname{tr}-0.02$ & & & & \\
\hline 19 & (-)-linalool & $52.0-74.6$ & $99.5-99.6$ & $13.2-20.4$ & $68.7-73.7$ & $65.2-66.1$ & $63.5-63.9$ & $7.8-17.9$ \\
\hline \multirow[t]{2}{*}{20} & $(+)-$ & $48.0-25.4$ & $0.5-0.4$ & $86.8-79.6$ & $31.3-26.3$ & $34.8-33.9$ & $36.5-36.1$ & $92.2-82.1$ \\
\hline & $\%$ & $0.05-0.46$ & $1.58-36.14$ & $0.02-0.31$ & $0.15-0.24$ & & $0.11-0.24$ & $0.17-0.8$ \\
\hline 21 & (-)-citronellal & $84.6-94.8$ & & $3.9-8.9$ & 77.0 & $72.8-81.0$ & $78.7-80.5$ & $37.4-52.6$ \\
\hline \multirow[t]{2}{*}{22} & $(+)-$ & $15.4-5.2$ & & $96.1-91.1$ & 33.0 & $27.2-19.0$ & $21.3-19.5$ & $62.6-47.4$ \\
\hline & $\%$ & & & $\operatorname{tr}-0.05$ & $\operatorname{tr}-0.04$ & & & $\operatorname{tr}-0.11$ \\
\hline 23 & (-)-linalyl acetate & & $99.7-99.8$ & & & & & \\
\hline \multirow[t]{2}{*}{24} & $(+)-$ & & $0.3-0.2$ & & & & & \\
\hline & $\%$ & & $11.80-41.36$ & & & & & \\
\hline 25 & $(+)$-terpinen-4-ol & $12.1-26.7$ & $15.0-21.7$ & $9.5-18.3$ & $28.8-29.2$ & $20.8-29.1$ & $19.3-20.4$ & \\
\hline \multirow[t]{2}{*}{26} & $(-)-$ & $87.9-73.3$ & $85.0-78.3$ & $90.5-81.7$ & $71.2-70.8$ & $79.2-70.9$ & $80.7-79.6$ & \\
\hline & $\%$ & $0.01-0.10$ & $\operatorname{tr}-0.29$ & $\operatorname{tr}-0.08$ & $0.04-0.70$ & & $0.04-0.17$ & \\
\hline 27 & $(-)-\alpha$-terpineol & $66.4-82.7$ & $21.2-54.2$ & $67.7-76.5$ & $84.1-89.6$ & $79.5-83.8$ & $77.4-78.0$ & $5.1-15.7$ \\
\hline \multirow[t]{2}{*}{28} & $(+)-$ & $33.6-17.3$ & $78.8-45.8$ & $32.3-23.5$ & $15.9-10.4$ & $20.5-16.2$ & $22.6-22.0$ & $94.9-84.3$ \\
\hline & $\%$ & $0.05-0.84$ & $0.03-0.13$ & $0.04-0.46$ & $0.21-0.80$ & & $0.16-0.37$ & $0.02-0.15$ \\
\hline
\end{tabular}


to evaluate particular behaviors due to the limited number of samples available. Therefore for this citrus oil it is simply reported the enantiomeric distribution determined for each sample.

\section{Lemon}

The chiral distribution of the components analyzed in the 92 samples of lemon are characterized by the prevalence, during the entire productive season of the levorotatory enantiomers of: $\alpha$-thujene, $\alpha$-pinene, camphene, $\beta$-pinene, sabinene, linalool, citronellal, terpinen-4-ol and $\alpha$-terpineol; the dextrorotatory enantiomer of limonene is always the most abundant; characteristic is the inversion of the excess of $\alpha$ - and $\beta$-phellandrene from levorotatory to the dextrorotatory during the season as shown in Figure 1. The range of the enantiomeric ratios determined in the 92 samples of lemon oils for linalool and $\alpha$-terpineol are wider than those previously reported by Mondello et al. 1996. This is due to the larger number of samples here analyzed and to seasonal variation. However the values reported by Mondello et al. 1996 are within the ranges here determined.
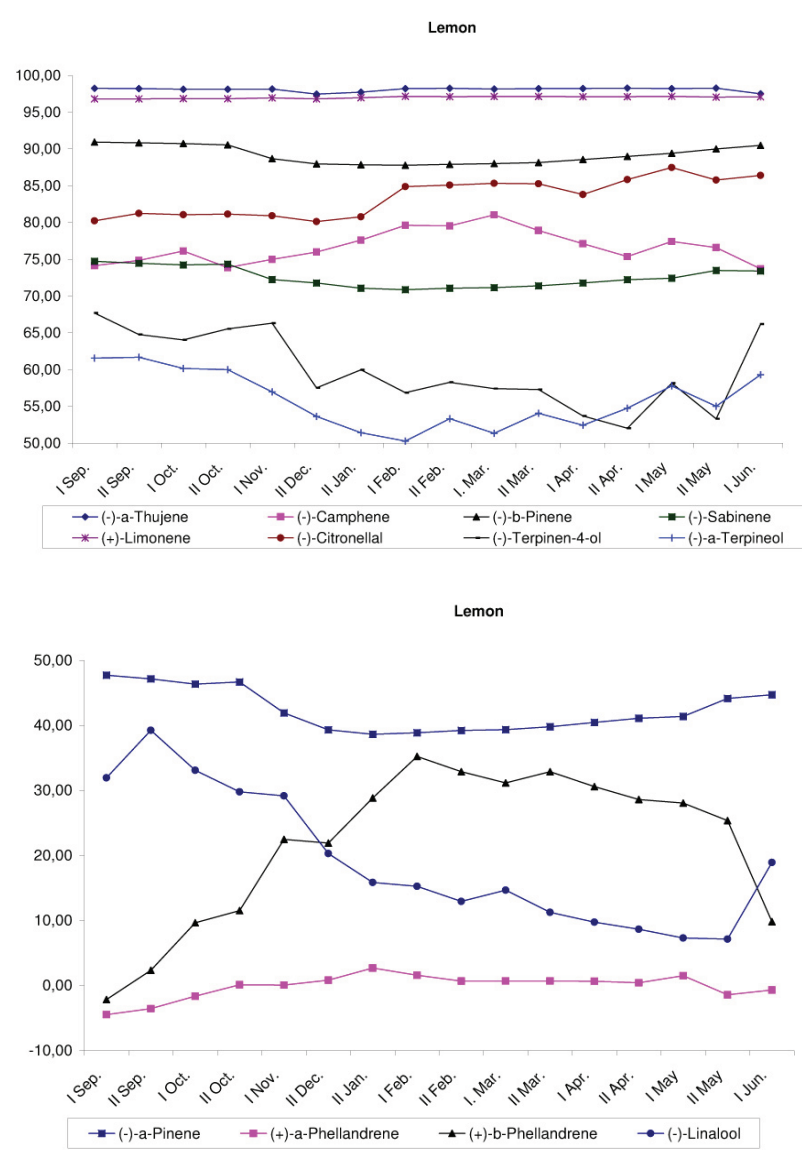

Figure 1. Seasonal variation of the enantiomeric ratios determined in Lemon oil.

\section{Bergamot}

In the eight samples analyzed the enantiomeric distribution of all components is almost constant during the season of production with the exception of $\alpha$-terpineol. The distribution of the enantiomers is characterized by the prevalence, during the entire productive season of the levorotatory enantiomers of: $\alpha$-thujene, $\alpha$-pinene, $\beta$-pinene, sabinene, camphor, linalool, terpinen-4ol, linalyl acetate; an almost racemic distribution is noticed for $\alpha$-phellandrene, with a very small excess of the (-)-isomer (3.95-7.67) in seven of the eight samples; the dextrorotatory isomer of limonene and of $\beta$-phellandrene are prevalent. Very characteristic is the inversion of the excess of $\alpha$-terpineol from levorotatory to the dextrorotatory during the season shown in Figure 2. From a comparison with previously published data by Dugo et al. (1999) the values of the enantiomeric excess of (-)- $\beta$-pinene, (-)-sabinene, (-)-terpinen-4-ol and (+)$\alpha$-terpineol are slightly different. These discrepancies could be addressed to the different period of production of the samples analyzed. This is particularly true for $\alpha$-terpineol, due to its great seasonal variation.
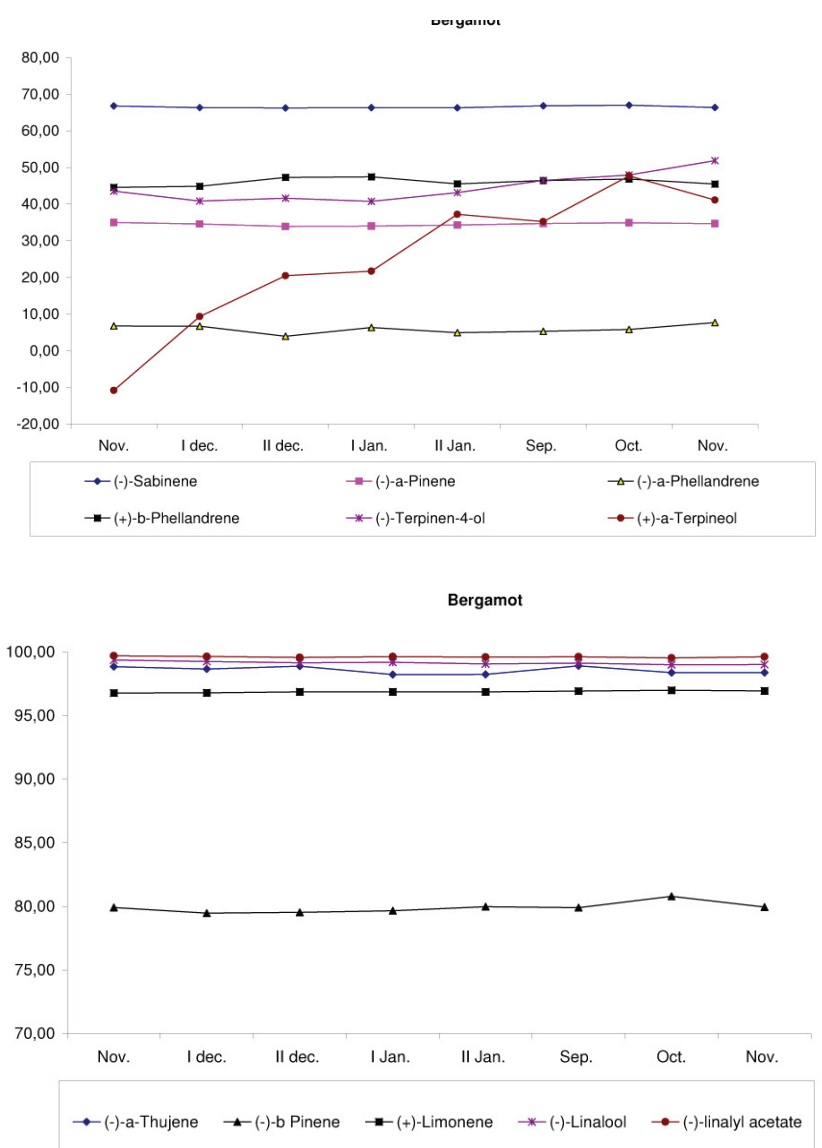

Figure 2. Seasonal variation of the enantiomeric ratios determined in Bergamot oil. 


\section{Mandarin}

The graphs in Figure 3 show the enantiomeric excess variation of 124 samples of mandarin oil collected during the entire productive season. The enantiomeric distribution is characterized by the prevalence of the following dextrorotatory isomers: camphene, $\beta$-pinene, sabinene, $\quad \beta$-phellandrene, limonene, linalool, citronellal. For $\alpha$-thujene, camphor, terpinene-4-ol and $\alpha$-terpineol exceeds the levorotatory isomer. The enantiomeric excess of (-)- $\alpha$-phellandrene inverts during the season, starting with a small negative value in September. However the variation during the season is very small, with a slight excess of the (-)-enantiomer from December until the end of the season. The range of the enantiomeric ratios determined in the 124 samples of mandarin oils for linalool and $\alpha$-terpineol are wider than those previously reported by Mondello et al. (1996). This is due to the larger number of samples here analyzed and to seasonal variation. This set of samples include results obtained for mandarin oils produced in September and in March, never considered in previous seasonal evaluations. However the values reported by Mondello et al. (1996) are within the ranges here determined.
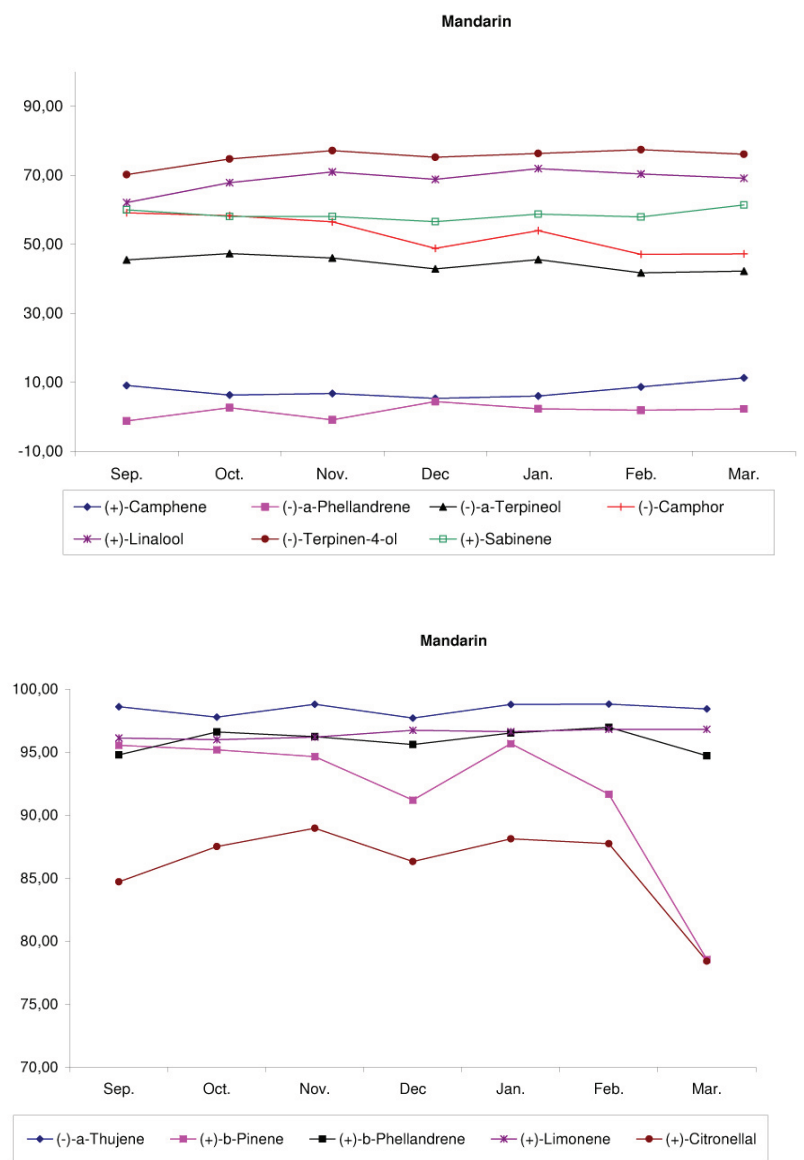

\section{Sweet orange}

In this essential oil the enantiomeric distribution is quite variable. However, in all the samples analyzed is noticed the prevalence of all dextrorotatory enantiomers with the exception of $\alpha$-thujene and $\beta$-pinene which show prevalence of the levorotatory isomer and for citronellal which shows an inversion. This great variability could be explained by the numerous different cvs. used to extract the essential oil which differently contribute to the industrial production during the season. To put some light on this aspect it may be necessary to manually extract the oils from fruits of selected cultivars during the season. Figure 5 shows the enantiomeric excess only of the enantiomers that show a regular trend during the season.

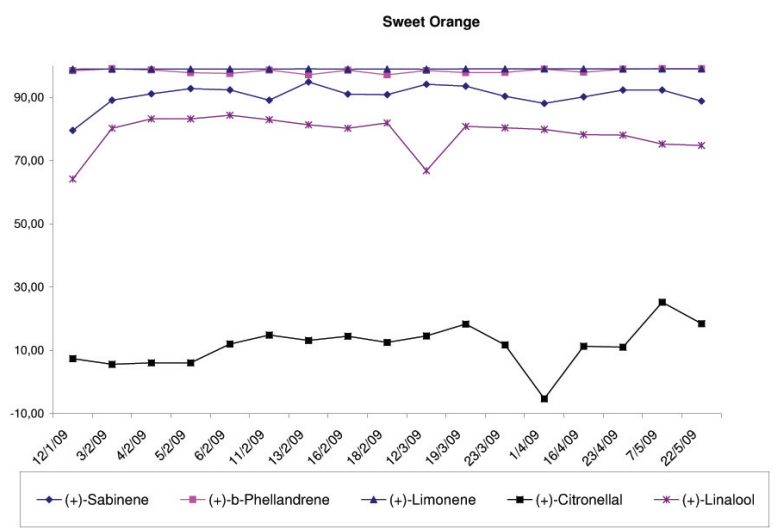

Figure 4. Seasonal variation of the enantiomeric ratios determined in Sweet orange oil.

Key and Persian limes

The enantiomeric distribution of these oils is characterized by the excess of the levorotatory isomer for all the components determined with the exception of limonene which, as in all citrus peel oils, shows a large excess of the dextrorotatory isomer. Between Key and Persian limes little differences can be noticed between the enantiomeric distributions of the components analyzed. The most evident is the lower enantiomeric excess of (-)- $\beta$-phellandrene in Persian lime. The enantiomeric excess of the monoterpene hydrocarbons are very similar between the two Key limes, with the exception, for small differences in distribution of $\alpha$ - and $\beta$ - phellandrenes. The alcohols show some differences as well: in Key lime type A the excess of (-)-linalool and (-)- $\alpha$-terpineol is slightly higher than in Key lime type B and in Persian; an opposite trend is observed for (-)-terpinen-4-ol, which is lower in Key lime type A.

Figure 3. Seasonal variation of the enantiomeric ratios determined in Mandarin oil. 


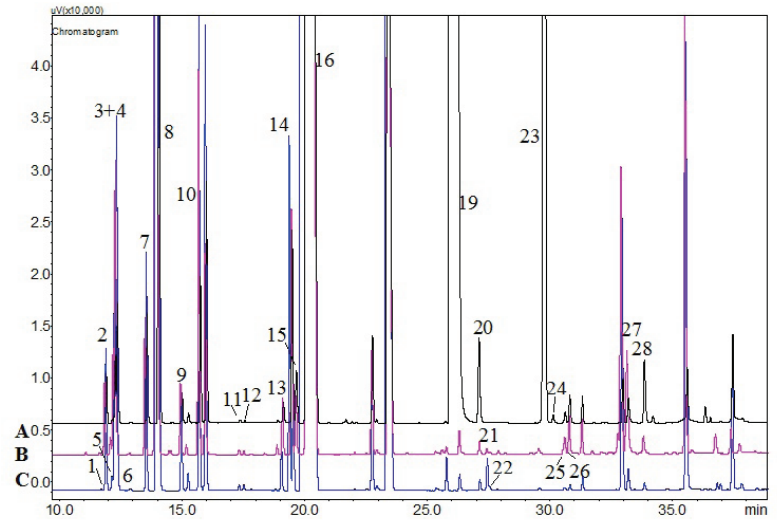

Figure 6. Overlay of the esGC chromatograms of the following cold-pressed essential oils: A. Bergamot; B. Key lime Type B; C. Lemon.

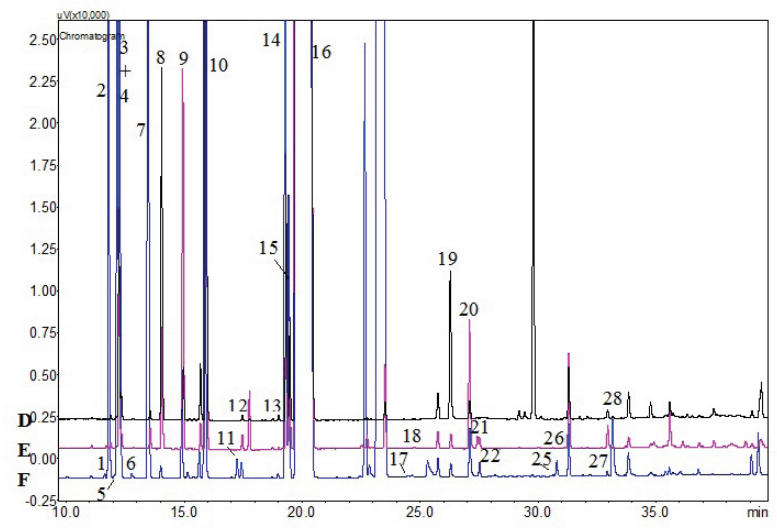

Figure 7. Overlay of the esGC chromatograms of the following cold-pressed essential oils: D. Bitter orange; E. Sweet orange; F. Mandarin.

\section{Bitter orange}

In the samples analyzed, when determined, it is noticed the prevalence of the dextrorotatory enantiomers of $\alpha$-pinene, camphene, $\beta$-phellandrene, limonene and $\alpha$-terpineol. For $\alpha$-thujene, $\beta$-pinene, $\alpha$-phellandrene, linalool and linalyl acetate the levorotatory enantiomer is the most abundant. Sabinene shows an almost racemic distribution in the commercial sample and a prevalence of the dextrorotatory enantiomer in all the other samples. Linalool shows in two of the four samples analyzed values of the enationtiomeric excess of the levorotatory isomer lower than that reported by Mosandl \& Juckelka, (1997) for genuine bitter orange oil. This results highlight the necessity of the acquisition of deeper knowledge on bitter orange essential oil, in consideration of the high commercial value of this niche product, hitherto not exhaustively studied.

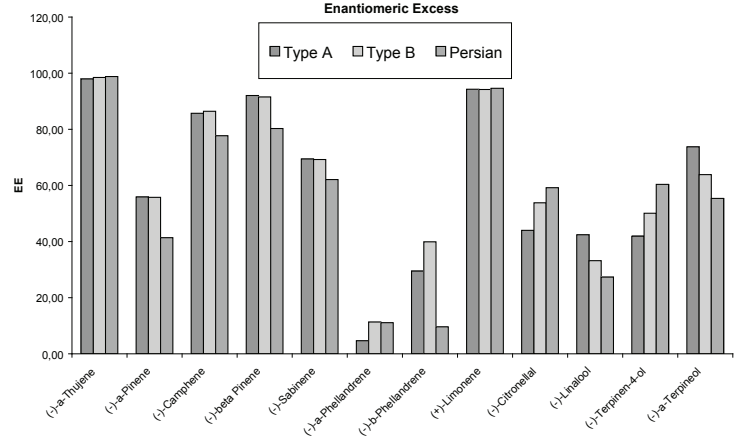

Figure 5. Graphical comparison of the enantiomeric excesses in Key type A and B, and Persian limes.

Based on the enantiomeric distribution of the components analyzed, the oils analyzed could be divided into two groups.

The first group, characterized by the prevalence of the same enantiomers or by values close to racemates ( $\alpha$ - and $\beta$-phellandrene). In this group fall lemon, bergamot and all the limes. Exception to this common behavior is given by the enantiomeric excess of $\alpha$-terpineol in bergamot oil which presents an opposite value at the beginning of the season. The esGC chromatograms of these citrus oils are reported in Figure 6.

The second group, composed by mandarin, sweet orange and bitter orange is characterized by similarities (mainly between mandarin and sweet orange) of the enantiomeric distribution of numerous components. Bitter orange could fall into the first group if are considered the enantiomeric distributions of linalool and linalyl acetate, but it well fits into the second group for the distribution of other components. The ratio of the $\alpha$-terpineol enantiomers are similar for sweet and bitter orange oils, while the values determined in mandarin are similar to those obtained for the citrus oils of the first group. The esGC chromatograms of these citrus oils are reported in Figure 7.

In conclusion the enantiomeric distributions determined for the fourteen components in the essential oils of seven different citrus specie was useful to determine: genuineness parameters; seasonal variation and to some extent the extraction technique. Characteristic are the enantiomeric ratios of linalool and linalyl acetate in bergamot, which are constant during the entire season and can be used to determine possible addition of synthetic or natural compounds obtained from sources different from bergamot; the enantiomeric ratios of linalool in sweet orange and bitter orange which allow to determine contaminations or fraudulent addition of the less valuable sweet orange to the more valuable bitter orange oil; the enantiomeric ratios of limonene provide a useful tool to reveal the addition in the more valuable citrus oils of products containing 
(-)-limonene, added to correct the optical rotation of oils reconstituted from sweet orange terpenes.

Lime oils present slight differences (Figure 6) between the two different species (Key vs. Persian). In Persian lime the enantiomeric excess of (-)- $\alpha$-pinene, (-)-camphene, (-)- $\beta$-pinene, (-)-sabinene, $(-)$ - $\beta$-phellandrene, (-)-linalool and (-)- $\alpha$-terpineol are always lower.

Table 2. Enantiomeric distribution determined in bitter orange oils by esGC and MDGC, and relative peak area \% determined by GC on the whole volatile fraction.

\begin{tabular}{|c|c|c|c|c|c|}
\hline & & \multicolumn{2}{|c|}{ Italy } & \multirow{2}{*}{$\begin{array}{c}\text { Egypt } \\
\text { Red }\end{array}$} & \multirow{2}{*}{$\begin{array}{l}\text { Egyp } \\
\text { Greer }\end{array}$} \\
\hline & & commercial & laboratory & & \\
\hline 1 & $(+)$ - $\alpha$-thujene & 10.3 & & 30.8 & 23.6 \\
\hline \multirow[t]{2}{*}{2} & $(-)-$ & 89.7 & & 69.2 & 76.4 \\
\hline & $\%$ & $0-0.02$ & & & \\
\hline 3 & $(+)-\alpha$-pinene & 89.6 & 97.4 & 97.4 & 96.9 \\
\hline \multirow[t]{2}{*}{4} & $(-)-$ & 10.4 & 2.6 & 2.6 & 3.1 \\
\hline & $\%$ & $0.29-0.89$ & & & \\
\hline 5 & (-)-camphene & 41.6 & 37.1 & 35.8 & 45.0 \\
\hline \multirow[t]{2}{*}{6} & $(+)-$ & 58.4 & 62.9 & 64.2 & 55.0 \\
\hline & $\%$ & $t r-0.01$ & & & \\
\hline 7 & $(+)$ - $\beta$-pinene & 2.3 & 4.3 & 7.9 & 6.1 \\
\hline \multirow[t]{2}{*}{8} & $(-)-$ & 97.7 & 95.7 & 92.1 & 93.9 \\
\hline & $\%$ & $0.10-0.18$ & & & \\
\hline 9 & $(+)$-sabinene & 49.4 & 72.5 & 80.6 & 75.4 \\
\hline \multirow[t]{2}{*}{10} & $(-)-$ & 50.6 & 27.5 & 19.4 & 24.6 \\
\hline & $\%$ & $0.09-0.45$ & & & \\
\hline 11 & (-)- $\alpha$-phellandrene & 74.9 & 99.9 & 100 & \\
\hline \multirow[t]{2}{*}{12} & $(+)-$ & 25.1 & 0.1 & 0 & \\
\hline & $\%$ & $t r-0.08$ & & & \\
\hline 13 & (-)- $\beta$-phellandrene & 5.7 & 1.9 & 1.1 & 0.6 \\
\hline \multirow[t]{2}{*}{14} & $(+)$ & 94.3 & 98.1 & 98.9 & 99.4 \\
\hline & $\%$ & $t r$ & & & \\
\hline 15 & (-)-limonene & 0.5 & 0.5 & 0.5 & 0.5 \\
\hline \multirow[t]{2}{*}{16} & $(+)-$ & 99.5 & 99.5 & 99.5 & 99.5 \\
\hline & $\%$ & $91.54-96.52$ & & & \\
\hline 19 & (-)-linalool & 89.8 & 60.7 & 61.1 & 80.2 \\
\hline \multirow[t]{2}{*}{20} & $(+)-$ & 10.2 & 39.3 & 38.9 & 19.8 \\
\hline & $\%$ & $0.06-0.37$ & & & \\
\hline 23 & (-)-linalyl acetate & 99.4 & 97.8 & & \\
\hline \multirow[t]{2}{*}{24} & $(+)-$ & 0.6 & 2.2 & & \\
\hline & $\%$ & $0.18-1.17$ & & & \\
\hline 25 & $(+)$-terpinen-4-ol & 71.5 & & & \\
\hline \multirow[t]{2}{*}{26} & $(-)-$ & 28.5 & & & \\
\hline & $\%$ & $t r-0.03$ & & & \\
\hline 27 & $(-)$ - $\alpha$-terpineol & 6.6 & 23.5 & 29.8 & 17.4 \\
\hline \multirow[t]{2}{*}{28} & $(+)-$ & 93.4 & 76.5 & 70.2 & 82.6 \\
\hline & $\%$ & $0.03-2.94$ & & & \\
\hline
\end{tabular}

Key lime Type A and B are obtained from the same fruits, but in Type A the oil is in contact with the juice and then separated by centrifuge. Between the two Key lime oils the enantiomeric purities are very similar, with the exception of those relative to the phellandrenes, and to the alcohols. The two hydrocarbons present a slight tendency to racemization in Type A. The enantiomeric excess of (-)-linalool and (-)- $\alpha$-terpineol, strangely increased in Type A. This is probably due to the formation of these components during the contact of the oil with the juice/pulp phase which occurs during the extraction of Key lime type A. A similar phenomenon was observed for $(+)$ - $\alpha$-terpinenol in bergamot oils recovered by screw press from solid residues (Mondello et al. 1998). In this case these authors assumed that the stereoselective formation of this alcohol could be due to presence of selected microorganisms responsible of this phenomenon, or to the enzymatic hydrolysis of the glycosidically bonded enantiomer. Terpinen-4-ol seams to exhibit a slight tendency to racemization, as predictable when acid catalyzed reactions occur.

Differences between the enantiomeric excess in Italian and Egyptian bitter orange oils are neglectable. In this case the geographic origin could be characterized by different analytical approach, such as the determination of isotopic ratios by IRMS.

\section{References}

Bisignano G, Saija A 2011. Biological activities of citrus essential oils. In: Citrus oils: Composition advanced analytical techniques, contaminants and biological activity. Dugo G, Mondello L (eds.) Taylor and Francis Group. Boca Raton, FL, USA. p. 529-548.

Bonaccorsi I, Dugo P, Trozzi A, Cotroneo A, Dugo G 2009. Characterization of mandarin (Citrus deliciosa Ten.) essential oil. Determination of volatiles, non-volatiles, physico-chemical indices and enantiomeric ratios. Nat Prod Commun 4: 1595-1600.

Dugo G, Cotroneo A, Bonaccorsi I, Trozzi A 2011. Composition of the volatile fraction of Citrus peel oils. In: Citrus oils: Composition advanced analytical techniques, contaminants and biological activity. Dugo G, Mondello L (eds.). Taylor and Francis group. Boca Raton, FL, USA. p. 1-162.

Dugo G, Sciarrone D, Costa R, Bonaccorsi I, Dugo P, Mondello L, Santi L Fakhry HA 2011a. Characterization of oils from the fruits, leaves and flowers of the bitter orange tree. J Essent Oil Res 23: 1-15.

Dugo G, Bonaccorsi I, Ragonese C, Russo M, Donato P, Santi L, Mondello L 2011b. Analytical characterization of mandarin (Citrus deliciosa Ten) essential oil. Flavour Fragr J 26: 34-46.

Dugo P, Ragonese C, Russo M, Sciarrone D, Santi L, Cotroneo A, Mondello L 2010. Sicilian lemon oil: composition of volatile and oxygen heterocyclic fractions and enantiomeric distribution of volatile components. $J$ 
Sep Sci 33: 3374-3385

Dugo P, Giuffrida D 2011. Carotenoids of Citrus oils. In: Citrus oils: Composition advanced analytical techniques, contaminants and biological activity. Dugo G, Mondello L (eds.). Taylor and Francis group. Boca Raton, FL, USA. p. 445-462.

Dugo P \& Russo M 2011. The oxygen heterocyclic components of citrus essential oils. In: Citrus oils: Composition advanced analytical techniques, contaminants and biological activity. Dugo G, Mondello L (eds.). Taylor and Francis group. Boca Raton, FL, USA. p. 405444.

Dugo G, Bartle KD, Bonaccorsi I, Catalfamo M, Cotroneo A, Dugo P, Lamonica G, McNair H, Mondello L, Previti P, Stagno d'Alcontres I, Trozzi A, Verzera A 1999. Advanced analytical techniques for the analysis of Citrus essential oils. Part. 2. Volatile fraction: LCHRGC and MDGC. Essenze Derivati Agrumari 69: 159-217.

Frum Y, Viljoen AM 2006. In vitro 5-lipoxygenase activity of three indigenous South African aromatic plants used in traditional healing and the stereospecific activity of limonene in the 5-lipoxygenase assay. J Essent Oil Res 18: 85-88.

Heuberger E, Hongratanaworakit T, Bohm C, Weber R, Buchbauer G 2001. Effects of chiral fragrances on human autonomic nervous system parameters and self-evaluation. Chem Senses 26: 281-292.

Kamatou GPP, Viljoen AM 2008. Linalool- A review of a biologically active compound of commercial importance. Nat Prod Commun 3: 1183-1192.

Mondello L, Costa R, Sciarrone D, Dugo G 2011. The chiral compounds of citrus oils. In: Citrus oils: Composition advanced analytical techniques, contaminants and biological activity. Dugo G, Mondello L (eds.). Taylor and Francis group. Boca Raton, FL, USA. p. 349404.

Mondello L, Verzera A, Previti P, Crispo F, Dugo G 1998. Multidimensional capillary GC-GC for the analysis of complex samples. 5. Enantiomeric distribution of monoterpene hydrocarbons, monoterpene alcohols and linalyl acetate of bergamot (Citrus bergamia Risso et Poiteau) oils. J Agr Food Chem 46: 4275-4282.

Mondello L, Dugo G, Dugo P, Bartle KD 1996. On-line HPLC-HRGC in the analytical chemistry of Citrus essential oils. Perfumer \& Flavorist 21: 25-49.

Mosandl A, Juchelka D 1997. The bitter orange tree-a source of different essential oils. In: Flavour Perception. Kruse H-P, Rothe M (eds.). Eigenverlag Deutsch Inst. F. Ernahrungsforsch. p. 321-331.

Ozek T, Tabanca N, Demrci F, Wedge DE, Husnu Can Baser K 2010. Enantiomeric distribution of some linalool containing essential oils and their biological activities. Records Nat Prod 4: 180-192.

Peana AT, D'Aquila PS, Panin F, Serra G, Pippia P, Moretti MDL 2002. Anti-inflammatory activity of linalool and linalyl acetate constituents of essential oils. Phytomedicine 9: 721-726.

Peana AT, Rubattu P, Piga GG, Fumagalli S, Boato G, Pipia P, De Montis MG 2006. Involvement of adenosine A1 and A2A receptors in (-)-linalool-induced antinociception. Life Sci 78: 2471-2474.

Ruberto G, Baratta MT 2000. Antioxidant activity of selected essential oil components in two lipid model systems. Food Chem 69: 167-174.

Sciarrone D, Schipilliti L, Ragonese C, Tranchida PQ, Dugo P, Dugo G, Mondello L 2010. Thorough evaluation of the validity of conventional enantio-gas chromatography in the analysis of volatile chiral compounds in mandarin essential oil: A comparative investigation with multidimensional gas chromatography. $J$ Chromatogr A 1217: 1101-1105.

\section{*Correspondence}

Ivana Bonaccorsi

Dipartimento Farmaco-chimico, Università di Messina V.le SS. Annunziata, 98168 Messina, Italy

ivabonaccorsi@unime.it

Tel. +390906766572

Fax: +39090358220 